\title{
The Correlation between Global Citizenship Perceptions and Cultural Intelligence Levels of Teachers
}

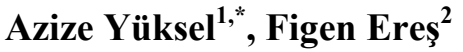 \\ ${ }^{1}$ Institute of Education Sciences, Gazi University, Ankara, Turkey \\ ${ }^{2}$ Faculty of Education, Gazi University, Ankara, Turkey
}

Copyright $\mathrm{O} 2018$ by authors, all rights reserved. Authors agree that this article remains permanently open access under the terms of the Creative Commons Attribution License 4.0 International License

\begin{abstract}
The increase of communication methods in the globalized world, the reduction of locality to a minimum in the economy and as a result of this, the migration from less economically developed countries to developed countries which in turn results in close interaction between ethnicities, all make it impossible for a homogenous society to exist and forces societies to embody a multicultural structure. The aim of this study is to determine the correlation between global citizenship perceptions and cultural intelligence levels of teachers. Global citizenship perceptions of teachers are at the level of "I partially agree". Within the context of global citizenship the highest perception of teachers is global competence, while their lowest perception is social responsibility. These results suggest that teachers' perceptions of global citizenship are not at a sufficient level. Teachers' cultural intelligence levels are at the level of "I partially agree". The highest level of teachers' cultural intelligence is identified to be in the sub-dimension of metacognitive cultural intelligence, while the lowest level is seen in the sub-dimension of cognitive cultural intelligence. These results suggest that cultural intelligence levels of teachers are inadequate. It has been determined that there is a low level of positive correlation between global citizenship perceptions and the cultural intelligence levels of teachers. Preserving and maintaining the existence of cultural differences with education must be considered as an essential right. It is believed that reviewing educational policies is necessary to increase the acknowledgement of cultural differences and to ensure that language differences are reflected throughout educational practices.
\end{abstract}

Keywords Global Citizenship, Cultural Intelligence, Teacher, School

\section{Introduction}

As a result of transformations experienced as of the $21^{\text {st }}$ century, we are living in an age in which interdependency has increased in a way that has never been observed in history, a period in which acting in unison is deemed an obligation rather than merely a necessity and life is maintained in a world which is virtually defined as a global village. Simultaneously with diversifying identities, we are facing a world culture that is becoming more and more similar is experienced. This process, which is regarded as a consequence of globalization, is felt in the reflection of the scientific innovations in as well as in many political, economic and cultural aspects, having a profound effect on daily life in many aspects of politics, economics and culture and affects daily life profoundly. Societies and individuals are engaging in activities that are bringing them closer and closer and even exceeding the borders of the countries in which they live. Many activities and relations such as the professions that are preferred, communication methods used, travel, trade operations, sports competitions, pop music have all gained the quality of surpassing borders and embodying an international identity. As a result, people from different countries come together to exchange ideas, services, and products, and have the opportunity to benefit from the experiences of different cultures. These experiences are indications of a transition from a national level of relationships and thought models into a thought and relationship model belonging to a dimension beyond nations [1]. With globalization, distance and time constraints have disappeared worldwide; as a result, people have increased their social and cultural interactions by coming together more in a world that is getting smaller [2]. According to Osler and Starkey [3], it is no longer possible to define citizenship within the borders of a country as a concept in such an environment. This process has revealed the concept of global citizenship.

Global citizenship is defined as being able to assess issues related to the world from different aspects, finding new solutions to these problems, interpreting global changes, analyzing the effects of these changes on individuals' lives, and being aware of the existence of different cultures [4]. According to McIntosh [5], global citizenship is expressed as creating and maintaining a network of relationships and connections throughout the lines of difference and discrimination as well as protecting this connection, while feeling and deepening deepening 
the senses of self-identity and integrity. Citizens are required to participate in global issues and take responsibility for fighting injustices [6]. According to Urry [7], global citizenship is not about belonging to a particular political community but about feeling, thinking and in the name of all people. Global citizenship involves questioning and critical thinking, discovering our views, values and assumptions in local and global dimensions, understanding the complexity of global issues and developing a multi-faceted perspective, and expanding the concept of social justice at both a local and global level [8]. In this context, the term includes concepts such as normative environment, global awareness, empathy between groups, valuing differences, social justice, intergroup cooperation, environmental sustainability, and responsibility to act [9].

Morais and Ogden [10], evaluated the concept in three dimensions as social responsibility, global competence and global civil participation, taking into account the certain theoretical and philosophical perspectives described in literature within the scope of global citizenship. Social responsibility is expressed as a level of interdependence and social anxiety towards others, society and the environment [11]. Individuals with social responsibility assess social problems and identify instances of global injustice and inequality [12]. They examine and respect different points of view and create social service ethics to address local and global issues [13]. Global competence is defined as being open-minded, making active efforts to understand others' cultural norms and expectations, and communicating knowledge and using it to work effectively outside the environment [14, 15]. Globally competent individuals are aware of their own abilities and limitations in intercultural meetings. Global civil participation is defined as recognizing local, national, and global community problems and demonstrating action and predisposition to issues such as volunteering, political activism, and social involvement [16]. As citizens, individuals contribute to voluntary work or help global civil organizations $[17,18]$.

Studies on global citizenship have brought the concept of cultural intelligence. In other words, it is possible to say that cultural intelligence In other words, it is possible to say that cultural intelligence is a theoretical extension of the hypotheses that was put forth by contemporary approaches with the aim of understanding intelligence and emerged with movement [19]. In an increasingly globalized world, the identification of skills that facilitate effective intercultural interaction is becoming even more important in all aspects of humanity from diplomacy to commercial and international assistance to peacekeeping operations [20]. In this context, cultural competence is defined as the ability with which most people minimize misunderstandings about individuals from other cultures, and cultural knowledge is known to have a positive influence on maximizing intercultural competence [21]. Cultural intelligence which expresses the cultural competency is described by Earley and Ang [22], as the ability of one to adapt effectively to different environments. Cultural intelligence is a set of skills that include intellectual, motivational, and behavioral components, focusing especially on solving intercultural problems [23].

With cultural intelligence, an individual can be skilled and flexible when gaining knowledge about culture; they will have the ability to act in accordance with the cultural structure they are communicating with, to adapt to the culture and reshape his/her structure of thought accordingly [24]. The individual may interpret the uncertain actions of foreigners from different cultures as if he/she belongs to that culture [25]. Cultural intelligence not only includes the knowledge necessary to understand cultural differences, but also strategic thoughts, fields of interests and behavioral consequences of the individual's interactions with different cultures [26]. A culturally intelligent person is one who has the ability to identify the information he/she has obtained, while paying attention to his/her position and the process of judgment [27].

Cultural intelligence is expressed as a multi-dimensional concept in literature [22, 28, 29]. Ang and Van Dyne [19], explain cultural intelligence with "4 Factor Model". One of these dimensions is metacognitive cultural intelligence. This dimension defines the degree of cultural awareness that a person has during intercultural exchanges. Individuals who approach new cultural interactions with an open-mind and who do not hesitate to question cultural assumptions have a high level of metacognitive cultural intelligence and are consciously aware of the cultural preferences of other individuals before and during the interaction [30]. The second dimension is cognitive cultural intelligence. Cognitive cultural intelligence reflects the knowledge of norms, practices, and contracts in different cultures from education and personal experience. It includes having knowledge about the economic, legal, socio-linguistic and interpersonal systems of different cultures and subcultures and the basic frameworks of cultural values. Individuals with cognitively high cultural intelligence understand the similarities and differences of cultures [23]. In this dimension, an individual should be regarded as a person who is aware of only some basic cultural differences and their effects on him/herself and others, rather than as an expert on a particular culture. Individuals with a high cognitive cultural intelligence have the ability to demonstrate the similarities and differences between cultures [30]. The third dimension is the motivational cultural intelligence. Motivational cultural intelligence is defined as the level of desire, interest and energy of an individual to achieve intercultural adaptation [26]. It is the ability of the individual to direct his/her attention and energy towards learning about places that vary culturally [23]. Motivational cultural intelligence is concerned with the individual's ability to think strategically [31]. The fourth dimension is behavioral cultural intelligence. In 
this dimension, cultural intelligence expresses the ability of an individual to demonstrate proper verbal and nonverbal actions while interacting with individuals from different cultures [30]. In its broadest sense, behavioral cultural intelligence is the ability of an individual to adapt his/her behavior in different cultural settings [32]. Behavioral cultural intelligence is based on having a broad repertoire and using a series of behaviors. Behavioral dimension, as an important component of cultural intelligence, generally reflects the most prominent feature of social interactions. At the same time, non-verbal behaviors within this dimension are particularly important because they behave as a silent language that communicates their meaning in silent and discreet ways [33].

For individuals to be able to learn the prevalent culture in the society which they live as well as the cultures that are of a minority quality in comparison to it, for them to achieve the knowledge, skills, and approaches to effectively communicate with these cultures, is only possible with the existence of an educational system composed with such a perspective [34]. Multicultural education that is provided as the result of such an understanding is defined as an approach which aims to ensure that individuals respect differences, emphasize that these differences are a value in education, embody all cultural diversities, gain the information and knowledge which enables them to see themselves from the view of other cultures, to gain better knowledge of themselves in this way and to respect different cultures, and how to behave in different ethnical groups [35]. School administrators, societies, and families have important duties to ensure that students achieve multicultural skills needed in the school and society $[36,37]$.

Teachers in particular play an important role in instilling tolerance, equality, respect for cultural differences, reconciliation, etc., which are among the principles of the concept of multicultural education as well as ensuring an equal opportunity of success for all students $[38,39]$. The fact that teachers have the knowledge and skills necessary to adapt to cultural differences is regarded important in developing a positive attitude towards education in multicultural settings. As cultural intelligence means that the individual has the skills and attitude required to adapt to intercultural differences, this quality shall help teachers to develop positive approaches in a multicultural education setting, to be aware of which behaviors, values, and attitudes shape the cultures of students, to be aware of the social and cultural aspects of learning [35]. Teachers' having an advanced level of cultural intelligence allows different cultures to be analyzed from multiple perspectives and for these to be shared in the classroom environment. As a result, teachers have the opportunity to achieve equal opportunity in the classroom in general. Besides, it is predicted that cultural intelligence shall also affect teachers' attitudes towards multicultural education and that teachers with advanced cultural intelligence shall have a more positive approach toward multicultural education [40].

Due to geopolitical and historical characteristics, Turkey has a multicultural society. However, in direction of the recently experienced developments, intensive immigration towards the country has led appearance of different immigrant types such as refugee, asylum seeker, illegal worker, and transit immigrants [41]. By the year of 2011, the process known as "the Arab Spring" has exercised control over countries in Middle East such as Tunisia, Egypt, Libya as well as Syria and battles and economic crisis in the countries have led many immigrants to Turkey. Hundred thousands of Syrian have fled from the regime pressure in their countries and taken refuge in neighboring countries such as Jordan, Lebanon, and Turkey and accordingly, Turkey has exposed intensive flurry of refugees [42]. By 2017, Turkey has become at the top in the list of countries with the most immigrants [43].

In the scope of this significance, the aim of this study is to determine the correlation between global citizenship perceptions and cultural intelligence levels of teachers. For this purpose, the answers to the following questions shall be sought:

1. What is the level of teachers' global citizenship perceptions?

2. Do teachers' global citizenship perceptions vary according to individual characteristics?

3. What are the cultural intelligence levels of teachers?

4. Do the cultural intelligence levels of teachers vary according to their individual characteristics?

5. What is the correlation between global citizenship perceptions and cultural intelligence levels of teachers?

\section{Methods}

\subsection{Model}

This study applies a descriptive and relational screening model to examine the correlation between teachers' perceptions of global citizenship and cultural intelligence.

\subsection{Population and Sample}

The population of the study is composed of teachers working in high schools in Isparta and its city center during the2017-2018 academic year. Within this scope, it is determined that there are 29 high schools in the universe of the study. The total number of teachers working in these high schools is 1,133 . The sample number of the study is 400. The stratified sampling method was used for the schools to be adequately represented in the study. Since the rate of teachers in each school is different, the Neyman sharing method was used in determining the sample size [44]. Demographic characteristics of teachers are given in Table 1 below. 
Table 1. Frequency and Percentage Distributions of Teachers' Demographic Information

\begin{tabular}{|c|c|c|c|c|c|c|}
\hline Variables & & 1 & 2 & 3 & 4 & Total \\
\hline \multirow{3}{*}{ Gender } & & Male & Female & & & \\
\hline & $\mathrm{n}$ & 236 & 164 & & & \\
\hline & $\%$ & 59 & 41 & & & 100 \\
\hline \multirow{3}{*}{$\begin{array}{c}\text { Professional } \\
\text { Experience }\end{array}$} & & $1-10$ years & $11-20$ years & 21-30 years & 31 and above & \\
\hline & $\mathrm{n}$ & 42 & 176 & 115 & 67 & \\
\hline & $\%$ & 10.5 & 44.0 & 28.8 & 16.8 & 100 \\
\hline \multirow{3}{*}{ Educational level } & & Associate Degree & Undergraduate & Master's Degree & $\mathrm{PhD}$ & \\
\hline & $\mathrm{n}$ & 5 & 325 & 64 & 6 & \\
\hline & $\%$ & 1.3 & 81.3 & 16.0 & 1.5 & 100 \\
\hline
\end{tabular}

Of the teachers having participated in the study, $59 \%$ are males and $41 \%$ are females. $10.5 \%$ of them have a professional experience of $1-10$ years, $44 \%$ have a professional experience of $11-20$ years, $28.8 \%$ have a professional experience of $21-30$ years, and $16.8 \%$ have a professional experience of 31 years or more. $1.3 \%$ of them have associate degrees, $81.3 \%$ have an undergraduate degree, $16 \%$ have a master's degree, and $1.5 \%$ have a $\mathrm{PhD}$ degree.

\subsection{Data Collecting Tool}

Two different scales were used to determine the global citizenship perceptions and cultural intelligence levels of teachers working in high schools.

\subsubsection{Global Citizenship Scale}

The "Global Citizenship Scale" developed by Morais and Ogden [10], was used to measure teachers' perceptions of global citizenship. The scale consists of 30 items and three sub-dimensions (social responsibility, global competence, and global civil participation). The scale was prepared in accordance with the "five-point Likert scale" which are "1) I strongly disagree 2) I disagree 3) I partially agree 4) I agree 5) I strongly agree". The reliability coefficient of the Global Citizenship Scale has been determined as .84 . The reliability coefficients calculated in the three sub-dimensions are determined as follows: social responsibility, .724; global competence, .741; and global civil participation, .869 . The total variance of the global citizenship scale explained by three factors is $51.735 \%$. The factor variance of the global civil participation sub-dimension explains $33.4 \%$ of the total variance (eigen value: 6.012 ), the factor variance of the global competence sub-dimension explains $11.445 \%$ of the total variance (eigen value: 2.06), the factor variance of the social responsibility sub-dimension explains $6.891 \%$ of the total variance (eigen value: 1.24 ). It has been concluded from the values obtained that the scale has a high degree of reliability.

\subsubsection{Cultural Intelligence Scale}

The "Cultural Intelligence Scale" developed by Van Dyne, Ang and Koh [33] was used to measure the cultural intelligence levels of teachers. The scale consists of 4 sub-dimensions: "metacognitive cultural intelligence", "cognitive cultural intelligence", "motivational cultural intelligence" and "behavioral cultural intelligence," and consists of 20 items in total. The scale was prepared in accordance with the "seven-point Likert scale": 1=strongly disagree, $7=$ strongly agree. The reliability coefficient of the Cultural Intelligence Scale has been determined as .937. Reliability coefficients of four sub-dimensions calculated within themselves were respectively identified as follows: metacognitive cultural intelligence, .887 ; cognitive cultural intelligence, .858; motivational cultural intelligence, .900; and behavioral cultural intelligence, .906. The total variance of the Cultural Intelligence Scale explained by four factors is $70.605 \%$. The factor variance of the metacognitive cultural intelligence sub-dimension explains $47.075 \%$ of the total variance (eigen value: 9.415)., the factor variance of the cognitive cultural intelligence sub-dimension explains $10.128 \%$ of the total variance (eigen value: 2.026 ), the factor variance of the motivational cultural intelligence sub-dimension explains $7.362 \%$ of the total variance (eigen value: 1.472 ) and the factor variance of the behavioral cultural intelligence sub-dimension explains $6.040 \%$ of the total variance (eigen value: 1.208 ). It has been concluded from the values obtained that the scale has a high degree of reliability.

\subsection{Analysis of the Data}

In the analysis of the collected data, the characteristics of dependent and independent variables were taken into account and the data was analyzed and interpreted. In order to determine the statistical analysis to be used, it was firstly checked whether the data showed a normal distribution. It was confirmed that the data distribution in both scales demonstrates a normal distribution and the t-test and variance analysis were chosen from amongst the parametric test techniques to test the sub-problems of the study. The Pearson Correlation Analysis was used to determine the correlation between teachers' perceptions of global citizenship and cultural intelligences.

\section{Findings}

As the result of the study, the correlation between 
teachers' global citizenship perceptions and cultural intelligence levels is presented according to study questions.

\subsection{Finding Regarding Teachers' Global Citizenship Perceptions}

Table 2. Teachers' Global Citizenship Perceptions

\begin{tabular}{|c|c|c|c|}
\hline Teachers & $\mathrm{N}$ & $\overline{\mathrm{X}}$ & $\mathrm{S}$ \\
\hline Social Responsibility & 400 & 2.29 & 0.7041 \\
\hline Global Competence & 400 & 3.36 & 0.5359 \\
\hline Global Civil Participation & 400 & 3.18 & 0.6318 \\
\hline $\begin{array}{c}\text { The Level of Global } \\
\text { Citizenship Perception }\end{array}$ & 400 & 3.06 & .44597 \\
\hline
\end{tabular}

According to the findings, teachers' global citizenship perceptions are at the level of "I partially agree $(\bar{X}=3.06)$. Within the context of global citizenship, the teachers' social responsibility perceptions are at the level of "I disagree" $(\bar{X}=2.29)$. Teachers' global competence perceptions are at the level of "I partially agree" $(\bar{X}=3.36)$. Teachers' perceptions in global civil participation are at the level of "I partially agree" $(\bar{X}=3.18)$. Within the context of global citizenship, teachers' highest level of perception is global competence and their lowest level of perception is social responsibility.

When global citizenship perceptions are compared to teachers' demographic characteristics, a significant differences were identified in terms of teachers' genders [ $t$ $(400)=-2.70, \mathrm{p}<.05]$. It has been observed that male teachers have a higher average of global citizenship perceptions than female teachers. In terms of the length of professional experience, there is no significant difference in global citizenship perceptions $[\mathrm{F}(3-396)=1,189$, $\mathrm{p}>$.05]. Significant differences were determined in the perceptions of teachers according to their education levels $[F(3-396)=4,393, p<.05]$. Teachers with master's degrees have higher global citizenship perceptions.

\subsection{Findings on the Cultural Intelligence Levels of Teachers}

Table 3. The Cultural Intelligence Levels of Teachers

\begin{tabular}{|c|c|c|c|}
\hline Teachers & $\mathrm{N}$ & $\overline{\mathrm{X}}$ & $\mathrm{S}$ \\
\hline $\begin{array}{c}\text { Metacognitive Cultural } \\
\text { Intelligence }\end{array}$ & 400 & 5.27 & 1.112 \\
\hline $\begin{array}{c}\text { Cognitive Cultural } \\
\text { Intelligence }\end{array}$ & 400 & 4.28 & 1.2594 \\
\hline $\begin{array}{c}\text { Motivational Cultural } \\
\text { Intelligence }\end{array}$ & 400 & 5.00 & 1.3186 \\
\hline $\begin{array}{c}\text { Behavioral Cultural } \\
\text { Intelligence }\end{array}$ & 400 & 4.67 & 1.3352 \\
\hline Cultural Intelligence Level & 400 & 4.76 & 1.03987 \\
\hline
\end{tabular}

According to the findings obtained, teachers' cultural intelligence levels are at the level of "I partially agree"
( $\bar{X}=$ 4.76). Metacognitive cultural intelligence of teachers is at the level of "I partially agree" ( $\bar{X}=5.27)$. Teachers' cognitive intelligence levels are at the level of "I partially agree" ( $\bar{X}=4.28)$. Teachers' motivational intelligence levels are at the level of "I partially agree" $(\bar{X}=5.0)$. Teachers' behavioral intelligence levels are at the level of "I partially agree" $(\bar{X}=4.67)$. The highest level of cultural intelligence in teachers is seen in the sub-dimensions of metacognitive cultural intelligence. The lowest level of cultural intelligence in teachers is seen in the cognition capability of cultural intelligence.

When the global intelligence levels of teachers were compared according to teachers' demographic characteristics, there is no difference in their cultural intelligence levels based on their genders $[t(400)=-.476$; $\mathrm{p}>.05]$ and professional experience $[\mathrm{F}(3-396)=1.305$, $\mathrm{p}>.05]$. There is a difference in teachers' cultural intelligence level based on their educational levels $[\mathrm{F}(3-396)=4.546, \mathrm{p}<.05]$. Teachers with a master's degree have higher averages.

\subsection{Analysis of the Data Findings on the Correlation between Global Citizenship Perceptions and Cultural Intelligence Levels of Teachers}

According to the findings, the correlation coefficient between teachers' global citizenship perception and cultural intelligence levels was found to be +0.30 . Accordingly, it is understood that there is a low level of positive correlation between global citizenship perceptions and cultural intelligence levels of teachers $(r=$ $0.300 ; \mathrm{p}<.01)$.

Table 4. The Correlation between Global Citizenship Perceptions and Cultural Intelligence Levels of Teachers

\begin{tabular}{|c|c|c|c|}
\hline & & $\begin{array}{c}\text { Global } \\
\text { Citizenship }\end{array}$ & $\begin{array}{c}\text { Global } \\
\text { Intelligence }\end{array}$ \\
\hline Global & Pearson Correlation & 1.00 & .300 \\
Citizenship & Sig. (2 tailed) &, & .000 \\
& $\mathrm{~N}$ & 400 & 400 \\
\hline Cultural & Pearson Correlation & .300 & 1.00 \\
Intelligence & Sig. (2 tailed) & .000 &, \\
& $\mathrm{~N}$ & 400 & 400 \\
\hline
\end{tabular}

\section{Conclusion and Discussion}

The aim of this study is to determine the correlation between global citizenship perceptions and cultural intelligence levels of teachers. According to the findings, teachers' global citizenship perceptions are at the level of "I partially agree". Within the context of global citizenship, teachers' highest perception is global competence, while their lowest perception is social responsibility. These results suggest that teachers' perceptions of global citizenship are not at a sufficient level. Global citizenship has a comprehensive political identity which includes active citizenship and widely supports the activity of 
demanding individual and group rights. Along with this, political virtues are expressed as the priority given to the fulfillment of civic responsibilities and the development of interest towards other people [45]. The competencies that global citizens must possess are knowledge and understanding, skills, values and attitudes. Individuals are expected to have skills in critical thinking, effective debate, to fight for justice and against inequality, to have respect for people, and to have cooperation and conflict resolution competencies. Together with this, self-regard encompasses feelings of empathy, responsibility, and respect for differences [46]. In this context, it can be stated that the teachers examined in this study do not have a sufficient degree of these values and competencies.

Studies performed on global citizenship education emphasize the importance of democracy and human rights. After an effective global citizenship education, students also have the opportunity to practice the knowledge which they have obtained in their personal lives, in the context of democracy and human rights [47]. Teachers with insufficient global citizenship perceptions shall negatively affect the quality of this educational process. Teachers are expected to guide students in terms of how they can gain new knowledge, what may interest them and how they should behave in order for them to gain both a local and global identity that is of a reflective nature with clearly defined boundaries [48]. However, in order to be able to provide this guidance, the perception of global citizenship must first be higher. According to the findings of the research, there is no difference in the perceptions of the teachers based on the amount of experience they have; however, the perceptions of male teachers and teachers who are more educated are higher.

According to the study results, teachers' cultural intelligence levels are at the level of "I partially agree". The highest level of cultural intelligence is seen in the sub-dimension of metacognitive cultural intelligence and the lowest level is seen in the sub-dimension of cognitive cultural intelligence. The findings are below normal. It can be said from these results that the cultural intelligence levels of the teachers are not sufficient. Cultural intelligence has become increasingly important in educational environments, with the contemporary classes being culturally mixed due to globalization. In this context, the teachers are expected to help their pupils be ready to live and work in culturally diverse societies and in a world with a global understanding. Teachers need to be culturally more intelligent in order to better understand their students in the globalizing world and to provide them with a more effective education [49]. In this context, it can be said that teachers experience difficulty in perceiving and interpreting cultural hints, about cultural knowledge, handling cultural information effectively, showing appropriate cultural behaviors, motivation for continuous learning and learning cultures [25]. For students to be able to develop their intelligence, it is first expected that teachers should be equipped with the necessary knowledge of cultural intelligence [50]. According to the findings of the study, there is no difference in cultural intelligence levels of teachers according to their gender and experience. However, more educated teachers have higher levels of cultural intelligence. With this finding, it can be said that education has an influence on the development of teachers' cultural intelligence.

Taking the findings of the study into account, the main recommendation of this study is to provide a global citizenship education and a cultural intelligence education. Also, awareness of prospective teachers and current teachers must be raised in understanding the concepts of global citizenship and cultural intelligence and having the competence to meet the requirements of being a global citizen. Undergraduate, master's, and doctorate degree courses may help as well as organizing discussions and encouraging teachers to read and develop an understanding of this issue may be beneficial. It is an obligation to raise future generations with certain qualities in order for them to find their place in globalized world. The greatest responsibility in this regard belongs to the teachers.

Teachers must be competent in terms of cultural diversity in order to be able to provide culturally sensitive teaching and commit themselves to the adaptation of it to the current education system [51]. It is necessary to analyze the complexity of society's transformation, changing societal demands, teaching and learning processes in order to define the teachers' jobs and determine their competencies. Contrary to what is known, field knowledge is less important than the teachers' knowledge of teaching methods and learning processes [52]. Teachers can better understand their students and their behaviors if they know the mother tongue, ethnic identity, and social classes of their students and how they relate themselves with the group to which they belong [35]. But if they are insensitive to the way in which students with different cultural sensitivities are able to demonstrate their success and continue to impose certain standards, they fuel inequality and cause them to fail even more [51]. It is inevitable that cultures which enter a school play a role and educators should be aware of the structure of the community and how success cannot be ensured unless there is collaboration between the home, family, and environment. Sustaining cultural differences through education should be considered as an essential right. It is believed that reviewing educational policies is necessary to increase the acknowledgement of cultural differences and to ensure that language differences are reflected throughout educational practices

According to the results of the study, it has been determined that there is a low level of positive correlation between global citizenship perceptions and cultural intelligence levels of teachers. In this context, it can be said that global citizenship $[53,54]$ and cultural 
intelligence [55] which are close to the concept of multiculturalism have little effect on each other. Therefore, it is another recommendation of this study that studies on multiculturalism, global citizenship, and cultural intelligence be examined in comparison with different demographic structures.

\section{REFERENCES}

[1] S. Toulmin. The ambiguities of globalization, Futures, Vol. 31, No.9/10, 905- 912, 1999.

[2] E. Bornman, N. Schoonraad. The many faces of globalization, Musaion, Vol.19, No.1, 83-114, 2001.

[3] A. Osler, H. Starkey. Changing Citizenship: Democracy and Inclusion In Education, Open University Press, New York, 2005.

[4] D. Burrows. World citizenship. Paper presented at the American Council on Education Regional Conference on New Directions in International Education, Beloit, Wisconsin, October, 2004.

[5] P, McIntosh. Gender Perspectives on Educating For Global Citizenship. In: Nodding N (ed.) Educating Citizens for Global Awareness. New York: Teachers College Press, 22-39 2005.

[6] Kubow, P., Grossman, D., Ninomiya, A. Multidimensional Citizenship. In. J.J. Cogan \& R. Derricott (Eds.), Citizenship for the twenty-first century: An international perspective on education (pp.131-150). London, UK: Kogan Page. 2004.

[7] J, Urry. Globalization and citizenship, Journal of World-System Research, Vol.5, No.2, 311-324,1999.

[8] OXFAM Global citizenship in the classroom: A guide for Teachers,http://www.oxfam.org.uk/education/global-citize nship/globalcitizenship-guides, 2015.

[9] S. Reysen, I. Katzarska-Miller. A model of global citizenship: Antecedents and outcomes, International Journal of Psychology, Vol. 48, No. 5, 858-870, 2013.

[10] D.B. Morais, A.C. Ogden. Initial development and validation of the global citizenship scale. Journal of Studies in International Education, Vol.15, No.5, 445-466, 2011.

[11] R. Falk. The Making of Global Citizenship. In B. Van Steenbergen (Eds.), The Condition of Citizenship (pp.39-50), Sage, London, 1994.

[12] J. Urry. Global Flows and Global Citizenship. In F.E. Isin (eds.), Democracy, Citizenship and the Global City, (pp. 62-78). Routledge, New York, 2000.

[13] J. Andrzejewski, J. Alessio. Education for global citizenship and social responsibility, Vol. 1, No. 2, 2-17, 1999.

[14] A. Dobson. Citizenship and the Environment, Oxford University Press, UK: Oxford, 2003.

[15] J. Westheimer, J. Kahne. What kind of citizen? The politics of educating for democracy. American Educational Research Journal, Vol. 41, 237-269, 2004.

[16] N. Noddings. Educating Citizens for Global Awareness, Teachers College Press, New York, 2005.

[17] J. H. Carens. Culture, Citizenship, and Community: Contextual Political Theory and Justice as Even Handedness, Oxford University Press, New York, 2000.

[18] I. Langran, E. Langran, K. Ozment. Transforming today's students into tomorrow's global citizens: Challenges for U.S. educators, New Global Studies, Vol.3, No. 1, 1-22, 2009.

[19] S. Ang, L. Van Dyne. Handbook on Cultural Intelligence: Theory, Measurement and Applications., M.E. Sharpe, Armonk, NY, 2008.

[20] P.J. Devitt. Cultural intelligence and the expatriate teacher: A study of expatriate teachers' constructs of themselves as culturally intelligent (Doctorial dissertation), 2014. https://ore.exeter.ac.uk/repository/handle/10871/15388.

[21] R.L. Wiseman, M.R. Hammer, H. Nishida. Predictors of intercultural communication competence, International Journal of Intercultural Relations, Vol.13, No. 3, 349 370, 1989.

[22] P.C. Earley, S. Ang. Cultural Intelligence: Individual Interactions Across Cultures, Stanford University Pres, California, 2003.

[23] K.Y. Ng, L. Van Dyne, S. Ang. Cultural intelligence: A Review, Reflections, and Recommendations for Future Research. In A. M. Ryan, F. T. L. Leong, F. Oswald (Eds.), Conducting Multinational Research Projects in Organizational Psychology (pp. 29-58), American Psychological Association, Washington, DC, 2012.

[24] D.C. Thomas, K. Inkson. Cultural Intelligence: People Skills For Global Business, Berrett-Koehler Publishers Inc., California, 2003.

[25] P.C. Earley, E. Mosakowski. Cultural intelligence, Harvard Business Review, 139-146, October, 2004.

[26] D. Livermore. Leading with Cultural Intelligence: The New Secret to Success, AMACOM, New York, 2010.

[27] H.C. Triandis. Cultural intelligence in organizations. Group and Organization Management, Vol. 31, No. 1, 20-26, 2006.

[28] D.C. Thomas, K. Inkson. Cultural Intelligence: Living and Working Globally, Berrett-Koehler Publishers Inc., California, 2009.

[29] E. Plum. Cultural Intelligence: The art of leading cultural complexity, Proceedings of IWIC'09, 293-296, 2009.https://dl.acm.org/citation.cfm?doid=1499224.14992 80

[30] S. Ang, L.Van Dyne, C. Koh, K.Y. Ng, J.K. Templer, C. Tay, N.A. Chandrasekar. Cultural intelligence: Its measurement and effects on cultural judgment and decision making, cultural adaptation and task performance, Management and Organization Review, Vol. 3, No.3, 335-371, 2007.

[31] P.C. Earley, R.S. Peterson. The elusive cultural chameleon: Cultural intelligence as a new approach to intercultural 
training for the global manager, Academy of Management Learning and Education, Vol. 3, No.1, 100-115, 2004.

[32] D. Livermore. The Cultural Intelligence Difference, AMACOM, New York, 2011.

[33] L. Van Dyne, S. Ang, C. Koh. Development and Validation of the CQS: The Cultural Intelligence Scale. In S. Ang, L. Van Dyne (Eds.), Handbook of Cultural Intelligence: Theory, Measurement, and Applications (pp.16- 41), M.E. Sharpe Inc., New York, 2008.

[34] G. Gay. Preparing for culturally responsive teaching, Journal of Teacher Education, Vol.53, No.2, 106-116, 2002.

[35] J.A. Banks. Introduction: Democratic Citizenship Education in Multicultural Societies. In J. A. Banks (Eds.), Diversity and Citizenship Education: Global perspectives (pp.3-15), Jossey-Bass, San Francisco, 2003.

[36] M. Van Geel, P. Vedder. The role of family obligations and school adjustment in explaining the immigrant paradox, Journal of Youth and Adolescence, Vol. 40, 187-196, 2011.

[37] K.J. Swick, G. Boutte, I. Scoy. Multicultural learning through family involvement, Dimensions, Vol. 22, No.4, 17-21, 1994.

[38] A. Başbay, Y. Kağnıcı. Çok kültürlü yeterlik algıları ölçeği: Bir ölçek geliştirme çalışması. Eğitim ve Bilim, Vol. 36, No. 161, 199-212, 2011.

[39] J. Le Roux. The concept of 'Ubuntu': Africa's most important contribution to multicultural education?, Multicultural Teaching, Vol. 18, No. 2, 43-46, 2000.

[40] M.Gezer, İ.F. Şahin. Çok kültürlü eğitime yönelik tutum ve kültürel zekâ arasındaki ilișkinin yem ile incelenmesi. Doğu Coğrafya Dergisi, Vol. 22, No.38, 173-188, 2017.

[41] M. Goh. Teaching with cultural intelligence: Developing multiculturally educated and globally engaged citizens, Asia Pacific Journal of Education, Vol.32, No.4, 395- 415, 2012.

[42] A. İçduygu. The Labour Dimensions of Irregular Migration in Turkey. CARIM research report. Robert Schuman Centre for Advanced Studies, European University Institute: Florence, 2006.

[43] A. Akgül, A.Kaptı, O.Ö. Demir. Göç ve kamu politikaları: Suriye krizi üzerine bir analiz [Migration and public policies: An analysis of the Syrian crisis], Global: A Journal of Policy and Strategy, Vol. 1, No. 2, 1-22, 2015.

[44] T. Yamane. Basic sampling methods, Publishing of Literature, 'Vol. 53, 2001.

[45] G. Stokes. Global citizenship, Ethos, Vol. 12, No. 1, 19-23, 2004.

[46] OXFAM. Global Citizenship guide: Teaching controversial issues, 2006 http://www.oxfam.org.uk/education/global-citizenship/glo bal-citizenshipguides

[47] L. Davies. Global citizenship: abstraction or framework for action?, Educational Review, Vol.58, No. 1, 5-25, 2006.

[48] J.A. Banks. Citizenship education and diversity: Implications for teacher education, Journal of Teacher Education, Vol.52, No.1, 5-16, 2001.

[49] D.S. Petrovic. How do teachers perceive their cultural intelligence?, Procedia Social and Behavioral Sciences, Vol. 11, 276-280, 2011.

[50] Syria Regional Refugee Response. Inter-Agency Information Sharing Portal, 2017. http://www.data.unhcr.org/syrianrefugees/regional.php

[51] G. Gay. Culturally responsive teaching principles practices and effects. In R. H. Milner, K. Lomotey (Eds.), Handbook of Urban Education (pp. 353-372). NY: Routledge, New York, 2014.

[52] J.M. Moreno. Learning to teach in the knowledge society, 2005.http://siteresources.worldbank.org/EDUCATION/Re sources/278200-1126210664195/1636971-1126210694253 /Learning_Teach_Knowledge_Society.pdf.

[53] Moon, S. Multicultural and global citizenship in a transnational age: The case of South Korea. International Journal of Multicultural Education, Vol. 12, No. 1, 1-15, 2010.

[54] D. Ortloff. Moving the Borders: Multiculturalism and global citizenship in the German social studies classroom, Educational Research, Vol. 53, No. 2, 137-149, 2011.

[55] M. Watkins, G. Noble. Thinking beyond recognition: Multiculturalism, cultural intelligence, and the professional capacities of teachers, Review of Education, Pedagogy, and Cultural Studies, Vol. 38, No. 1, 42-57, 2016. 